\title{
Determination of Acceleration for Belt Conveyor Speed Control in Transient Operation
}

\author{
Daijie He, Yusong Pang, and Gabriel Lodewijks
}

\begin{abstract}
Speed control has been found a feasible mean to reduce the energy consumption of belt conveyors. However, the current research has not taken the determination of the acceleration in transient operation into account sufficiently. With respect to the belt tension rating, demanded safety factor and the ratio between belt tension before and after drive pulley, this paper presents an approach to estimate the acceleration time. Case with specific horizontal belt conveyor is studied. The simulations with finite element model are carried out to analyze the belt dynamic behaviors in transient operation. Further simulations are carried out to get the optimum acceleration time.
\end{abstract}

Index Terms-Speed control, belt conveyor, estimate acceleration, transient operation, dynamic behavior.

\section{INTRODUCTION}

Belt conveyors play an important role in continuous dry bulk material transport and logistics distribution. Belt conveyors also have been proven to be one of the most efficient means for transporting bulk solid materials. There are large amount of conveyors in operation in mining industry, coal fired power plants, steel industry and dry bulk terminals [1].

In the past decades, several different energy saving systems are designed to reduce the energy consumption of belt conveyor system. Based on different objects of the belt conveyor, the different energy saving approaches are classified into four groups [2], [3] methods applying energy efficient components, for example, new belt with lower frictional resistance factor or with smaller weight [4], new types of idler sets [5], [6] or high efficient motors [7]; methods optimizing the conveyor layout [8]; methods accounting the operational philosophy, for example, the time-of-use tariff [2]; and methods optimizing the drive operation, such as controlling motor sequences [9] or adjusting the conveyor speed [10]-[12]. The method adjusting conveyor speed is called speed control. In this paper, the speed control will be investigated as after applying other three methods, this method is still probable to further receive energy savings.

In general, the belt conveyor runs at its nominal speed with

Manuscript received October 29, 2014; revised January 12, 2015. The first author is sponsored by the China Scholarship Council (File No.201306990010).

The authors are with the Department of Marine and Transport Technology, Faculty of Mechanical, Maritime and Materials Engineering, Delft University of Technology, Mekelweg 2, 2628 CD, Delft, Netherlands (e-mail: D.He@tudelft.nl, Y.Pang@tudelft.nl, G.Lodewijks@tudelft.nl) the average utilization of cross-section less than $100 \%$. Standard DIN 22101 [13] implies lowering the belt speed and maximizing the material filling rate up to the possible peak can result in a considerable reduction of power consumption. This is speed control [14], [15]. Although the case study in [16] suggested that the speed control might cause the increase of power consumption, more applications of belt conveyor system with variable speed drive(s) certified that speed control can turn the power savings of conveyor system into reality [12], [15].

In [15], Pang states that the unexpected high ramp rate of speed increases the risks of shorting the lifetime of belt and motor, even damaging the conveyor structure. However, the current investigations of speed control mainly focus on the methods of estimating the energy savings via speed control [12], [17], and the algorithms determining the reference speed [15], [18]. There is a lack of knowledge on deciding the permitted acceleration and the demanded acceleration in transient operation. Here, the transient operation is the speed regulation process, especially in the acceleration procedure where the original speed of conveyor is not zero.

In this paper, the method estimating the permitted acceleration and the demanded acceleration time is described. Simulations with finite element model are carried out to correct the demanded acceleration time. With respect to the belt tension rating, the demanded safety factor and the ratio between the belt tension before and after the drive pulley, Section II presents the estimation of acceleration. Section III introduces the finite element model. In Section IV, a specified horizontal conveyer system is studied and the simulation results are given and the optimum acceleration time is suggested. The last section is the conclusion.

\section{Estimation of Permitted AcCeleration}

An approximation of permitted acceleration in start-up process has been represented by Lodewijks [19] and an application is given in [20]. In transient operation, this approximation is borrowed to rough estimate the permitted acceleration and demanded acceleration time.

In the transient operating condition, the main risks of conveyor system are belt-breaking at the belt splicing area and slipping between the belt and the drive pulley. In this paper, these two constrains are taken into account to decide the permitted acceleration and the demanded acceleration time in transient operation.

Standard DIN 22101 [13] states that when designing a belt conveyor system, the tension rating of the specified belt must satisfy the following formula: 


$$
k_{N} \geq \frac{k_{\text {sta }}}{1-r_{\text {Verb }}} S_{B}\left(\frac{k_{\text {insta }}}{1-r_{\text {Verb }}} S_{A, \min }\right)
$$

In the above equation following values are:

$k_{N}$ - nominal rupture force of specified belt

$k_{\text {sta }}$ - belt stress in steady operating condition

$S_{B}$ - safety factor in steady operating condition

$r_{\text {Verb }}$ - loss of strength in the belt joint

In non-steady operating condition, including transient operation, the following equation must be fulfil to reduce the risks of breaking:

$$
k_{\text {insta }} \leq \frac{k_{N}}{1-r_{\text {Verb }}} S_{A}
$$

where

$k_{\text {insta }}$ - belt stress in transient operation

$S_{A}$ - safety factors in transient operation

Substituting (1) and (2), the permitted belt tension in transient operation can be obtained by:

$$
k_{\text {insta } \max }=\frac{k_{s t a} S_{B}}{S_{A, \min }}
$$

Generally, in normal operating conditions, the safety factor is 8.0 in steady operating condition and 5.4 in transient operation [13]. In steady operating condition, the belt stress is defined as the belt traction force related to the belt width [13], [19]:

$$
k_{s t a}=\frac{F_{1}}{B}
$$

where

$F_{1}$ - belt tension before the drive pulley in steady operation

$B$ - the width of specified belt.

And in transient operation, the belt stress is

$$
k_{\text {insta }}=\frac{F_{1 A}}{B}
$$

where

$F_{1 A}$ - belt tension before drive pulley in transient operation

Combining equations (3) to (5) gives the permitted belt tension $F_{1 A, \max }$ in transient operation:

$$
F_{1 A, \max }=\frac{F_{1} S_{B}}{S_{A}}
$$

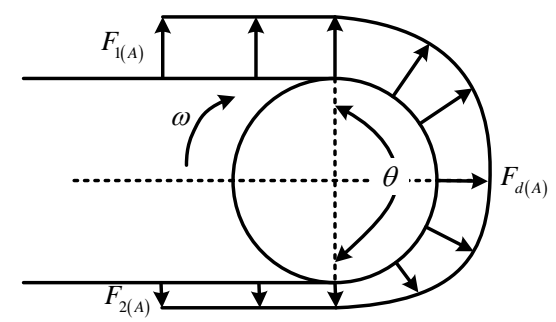

Fig. 1. Tensile forces exerted on the belt [19].

As Fig. 1 illustrates, the belt tension before the drive pulley equals the belt tension after the drive pulley adding the driving force:

$$
\begin{aligned}
& F_{1}=F_{2}+F_{d} \\
& F_{1 A}=F_{2 A}+F_{d A}
\end{aligned}
$$

where

$F_{1}$ - belt tension after the drive pulley in steady operating condition

$F_{1 A}$ - belt tension after the drive pulley in transient operation

$F_{d}$ - drive force of pulley in steady operating condition

$F_{d A}$ - drive force of pulley in transient operation

In transient operation, the peripheral driving forces on the drive pulley(s) equal the forces required to overcome the motional resistances and the extra driving forces caused by the acceleration,

$$
F_{d A}=F_{d}+F_{a c}
$$

where

$F_{a c}$ - extra driving forces caused by the acceleration

Supposing in transient operation, the belt tension $F_{2 A}$ after the drive pulley equals that $F_{2}$ in steady operating condition, combining (6) to (8) yields the maximum extra drive force of pulley $F_{a c, \max }$ in transient operation:

$$
F_{a c, \max }=\left(F_{2}+F_{d}\right) \frac{S_{B}-S_{A}}{S_{A}}
$$

In steady operation, the drive force of pulley equals the total motional resistances needed to overcome. DIN 22101 [13] states that the motional resistances can be subdivided into four parts: primary resistances $F_{H}$, secondary resistances $F_{N}$, slope resistances $F_{S t}$ and special resistances $F_{S}$,

$$
F_{d}=F_{H}+F_{N}+F_{S t}+F_{S}
$$

If the special resistances are not taken into account then (10) can be rewritten as [12][14]:

$$
F_{d}=C f L g\left[m_{\text {roll }}^{\prime}+\left(2 m_{\text {belt }}^{\prime}+m_{\text {bulk }}^{\prime}\right) \cos \delta\right]+m_{\text {bulk }}^{\prime} g H
$$

where

$C$ - secondary resistances coefficient

$f$ - artificial friction coefficient,

$L$ - length of conveyor,

$g$ - the gravitational acceleration,

$m_{\text {roll }}^{\prime}$ - average mass per unit length due to rotating rolls

$m_{\text {belt }}^{\prime}$ - mass of belt per unit length

$m_{\text {bulk }}^{\prime}$ - average mass of specified bulk materials on the belt per unit length

$\delta$ - average angle of inclination of the conveyor installation

$H$ - lifting height of the conveyor between the loading area and the discharging area

If the lifting height is too small to ignore, for instance, in case of horizontal conveyor system, the influence of lifting height and the inclination angle are negligible:

$$
F_{d}=C f L g\left[m_{\text {roll }}^{\prime}+\left(2 m_{\text {belt }}^{\prime}+m_{\text {bulk }}^{\prime}\right)\right]
$$


According to the Newton's second law of motion, the forces to overcome the inertia are

$$
a=\frac{F_{a c}}{L\left(m_{\text {roll }}^{\prime}+2 m_{\text {belt }}^{\prime}+m_{\text {bulk }}^{\prime}\right)}
$$

Then substituting (9) and (12) in (13) yields the permitted maximum acceleration

$$
a_{\text {max }, \text { break }}=\left(\frac{F_{2}}{L\left(m_{\text {roll }}^{\prime}+2 m_{\text {belt }}^{\prime}+m_{\text {bulk }}^{\prime}\right)}+C f g\right) \frac{S_{B}-S_{A}}{S_{A}}
$$

where

$a_{\text {max,break }}$ - permitted maximum acceleration honoring the belt tension rating and safety factor

Another constrain of permitted acceleration is the wrap factor which relates to the wrap angle of belt around the pulley(s) and the coefficient of friction between belt and pulley(s). According to Euler-Eytelwein formula [21], in transient operation, the ratio between the belt tension before and after the drive pulley is limited as [13], [19], [22]

$$
\frac{F_{1 A}}{F_{2 A}} \leq e^{\mu \alpha}
$$

in which

$\mu$ - coefficient of friction between belt and drive pulley

$\alpha$ - wrap angle of belt around the pulley(s)

Otherwise, the unexpected slip between the belt and the drive pulley might occur and the slip always increases the wear of belt. Combining (7) and (15) declares the permitted maximum driving force $F_{d A \text {, max }}$ in transient operation:

$$
F_{d A, \max }=\left(e^{\mu \alpha}-1\right) F_{2}
$$

Then substituting (8), (12) and (16) in (13) yields the permitted acceleration which honors the ratio between the belt tension before and after drive pulley:

$$
a_{\max , \text { slip }}=\frac{\left(e^{\mu \alpha}-1\right) F_{2}}{L\left(m_{\text {roll }}^{\prime}+2 m_{\text {belt }}^{\prime}+m_{\text {bulk }}^{\prime}\right)}-C f g
$$

where

$a_{\text {max,slip }}$ - permitted acceleration honoring the ratio between the belt tension before and after drive pulley

With regard to risks of both breaking and slipping, the permitted acceleration $a_{\max }$ in transient operation equals

$$
a_{\max }=\min \left\{a_{\text {max }, \text { break }}, a_{\text {max }, \text { slip }}\right\}
$$

In recent years, several acceleration profiles are designed as in Fig. 2. Because this paper mainly discusses the method deciding the acceleration and the acceleration time, so the details of acceleration profiles and their influences to belt dynamics are not further investigated in this paper. But the figure clearly shows that with different acceleration profile, the required acceleration time is quite different. To get a universal mathematical expression of acceleration time, the profile coefficients are introduced, which are associated with acceleration profiles, and the values of these coefficients are are given in Table I. Then the required minimum acceleration time $T_{a \text {, min }}$ can be presented as

$$
T_{a, \min }=C^{*} \frac{\Delta V}{a_{\max }}
$$

\begin{tabular}{|c|c|c|c|c|}
\hline $\begin{array}{l}\text { Acceleration } \\
\text { profile }\end{array}$ & Rectangular & $\begin{array}{l}\text { Sinusoi } \\
\text { d }\end{array}$ & Deltoid & Parabolic \\
\hline Coefficient $\mathrm{C}^{*}$ & 1 & $\pi / 2$ & 2 & 1.5 \\
\hline
\end{tabular}

where

$$
\begin{aligned}
& \Delta V \text { - speed regulation range } \\
& C^{*} \text { - profile coefficient }
\end{aligned}
$$

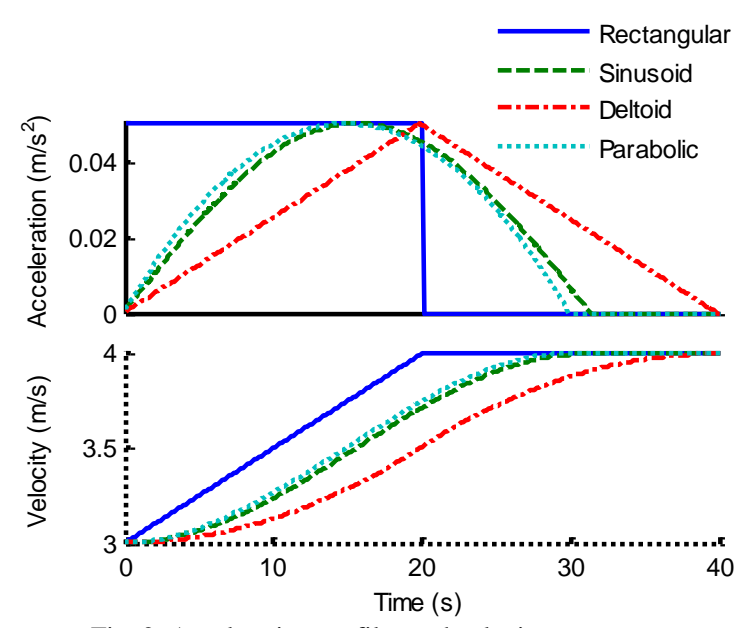

Fig. 2. Acceleration profiles and velocity curves.

TABLE I: PROFILE COEFFICIENT WITH VARIOUS ACCELERATION PROFILES

\section{FINITE ELEMENT MODEL}

In the above section, the method deciding the acceleration in transient operation has been described in detail. However, it should be pointed out that the equations neglect the effect of dynamics and hysteresis, and based on the practical experiences the demanded acceleration time is usually larger than that calculated. To analyze the belt dynamics and to correct the demanded acceleration time, simulations are carried out. The simulation is based on the finite element model.

Belt conveyor system is a complicated system with thousands of components and almost every conveyor system has its own unique layout and structure. A typical long belt-conveyor geometry is illustrated in Fig. 3 to help understand the belt conveyor and the finite element model theory.

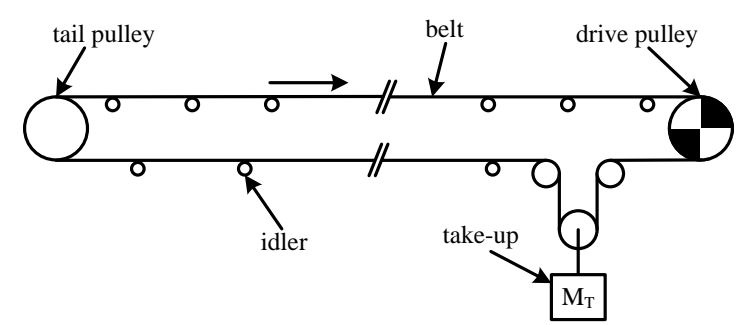

Fig. 3. Typical belt conveyor geometry [19]. 
For a large-scale belt conveyor system, the length of conveyor belt is much larger than the width and thickness. In many situations, it is eligible to analyze the belt dynamics and behavior with one-dimensional model [19]. And in the axial direction, the conveyor belt shows visco-elastic property. Based on the visco-elastic theory, several famous dynamic models have been built to simulate and analyze the dynamics of conveyor belt: Maxwell model, Kevin/Voigt model, three-element model which Kevin/Voigt model and elastic element are in series [23] and five element composite rheological model [24], etc. Meanwhile, these models have already been successfully employed to study the dynamic characteristics of conveyor belt [20], [25].

To analyze the conveyor dynamics in transient operation, the belt element composite model is built as Fig. 4. In Fig. 4, the symbols of $F_{i}, k_{i}, h_{i}, c_{i}$ and $m_{i}$ represent the equivalent tensile force, spring coefficient, viscous damping coefficient, Coulomb frictional coefficient and the reduced mass of the $i^{\text {th }}$ segment, respectively.

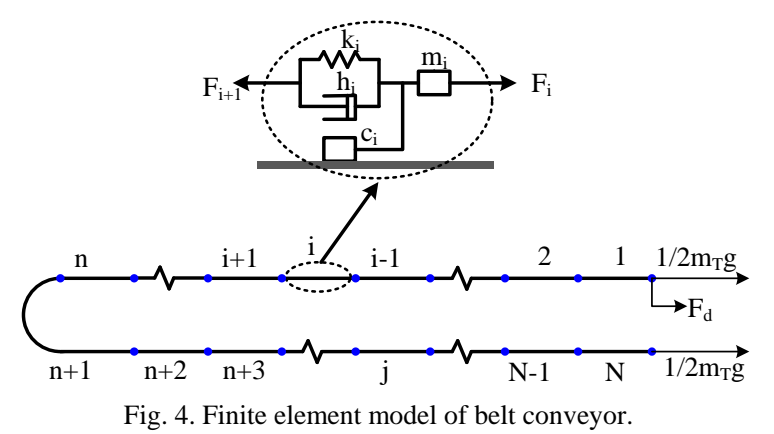

With Newton's second law, the mathematical expression of belt can be expressed as:

$$
\ddot{\mathbf{X}}=\frac{\mathrm{F}-\mathbf{K X}-\mathbf{H} \dot{\mathbf{X}}-\mathbf{C}(\mathbf{M}, \dot{\mathbf{X}}, \mathbf{F})}{M}
$$

where

$$
\begin{aligned}
& M \text { - matrix of unit mass } \\
& H \text { - matrix of damping constants } \\
& K \text { - matrix of elasticity constant } \\
& \ddot{\mathbf{X}} \text { - column vector of acceleration } \\
& \dot{\mathbf{X}} \text { - column vector of speed } \\
& \mathbf{X} \text { - column vector synthetic displacement } \\
& F \text { - column vector of driving force }
\end{aligned}
$$

$\mathbf{C}(\mathbf{M}, \dot{\mathbf{X}}, \mathbf{F})$ - column vector of Coulomb friction.

\section{CASe Study}

\section{A. Over View}

In this section, a long horizontal belt conveyor shown in Fig. 5 is studied.

A five layer fabric belt EP 500/5 is employed to transport the coal from one station to another, and the distance between the two stations $L_{\text {conv }}$ is $1000 \mathrm{~m}$ and the nominal capacity $Q_{n}$ is $2500 \mathrm{t} / \mathrm{h}$. With Young's modulus $E_{b} 340.917 \mathrm{MPa}$, unit mass $m_{\text {belt }}^{\prime} 14.28 \mathrm{~kg} / \mathrm{m}$, cross-section area $A 0.01235 \mathrm{~m}^{2}$ and width $B 1.2 \mathrm{~m}$, the belt is tensioned by a $5200 \mathrm{~kg}$ take-up device. The carrying part of belt is supported by three-roll idler station, and the average mass of idlers per unit length is $14.86 \mathrm{~kg}$; the return part is supported by one-roll idlers, and the average mass of idlers per unit length is $7.72 \mathrm{~kg}$. And spring factor and damping factor can be obtained [26] by:

$$
\begin{gathered}
k_{i}=\frac{E_{b} A}{L_{i}} \\
h_{i}=\frac{E_{b} A \tau}{L_{i}}
\end{gathered}
$$

where $L_{i}$ is length of $i^{\text {th }}$ segment and $\tau$ is viscous hysterics coefficient, and here the viscous hysterics coefficient is set as 1.0. The friction coefficient $\mu$ between the drive pulley and the belt is 0.35 , and the wrap angle $\alpha$ of the belt on the drive pulley is $180^{\circ}$, and the artificial friction coefficient $f$ is 0.018 .

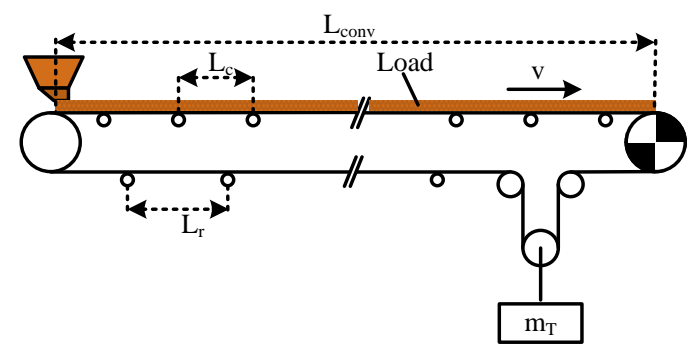

Fig. 5. Horizontal belt conveyor lay-out [19].

\section{B. Simulation Results}

Conveyor belt dynamics is simulated with belt fully loaded and in the simulation, the variable voltage and variable frequency drive control is taken into account to ensure the acceleration curves on the drive pulley following the defined acceleration profile. Here, the sinusoid acceleration profile is applied, and during the acceleration process, the instantaneous acceleration equals

$$
a(t)=\frac{\pi}{2} \frac{\Delta V}{T_{a}} \sin \frac{\pi t}{T_{a}}
$$

Assuming that the secondary resistance factor $C$ is set to 1.08 , the minimum safety factor $S_{A}$ and $S_{B}$ respectively equal 5.4 and 8.0, and the original speed is $3 \mathrm{~m} / \mathrm{s}$. Then based on (14), (17), (18) and data in Table I, the conveyor is expected to reach the reference speed $5 \mathrm{~m} / \mathrm{s}$ in 37 seconds.

Fig. 6 illustrates the conveyor dynamics of speed in transient operation. During the speed regulation procedure, the head pulley speed increases smoothly and at the time point $37 \mathrm{~s}$, the head pulley reaches the desired speed. Unlike that of head pulley, at the beginning of acceleration process, the speed of tail pulley has only little changes. After few seconds delay, the tail pulley starts to accelerate and at the time point $21.6 \mathrm{~s}$, the tail pulley speed overtakes the head pulley, and at the time point $35 \mathrm{~s}$, the speed of tail pulley reaches the peak $5.25 \mathrm{~m} / \mathrm{s}$. After that the speed of tail pulley begin its long period fluctuation around the demanded speed.

As discussed, during the transient operation, the main risks to belt are breaking at the splicing area and slipping with the drive pulley. To reduce the chances of belt breaking, in transient operation, the actual safety factor is expected to be larger than the demanded, 5.4. Fig. 7 illustrates the actual 
safety factor in transient operation. The figure shows at the time point $20 \mathrm{~s}$, the actual safety factor reaches its bottom, around 5.8, which is larger than the demanded. Therefore, in this acceleration process, the possibilities of belt breaking caused by the unexpected tensile force are very low.

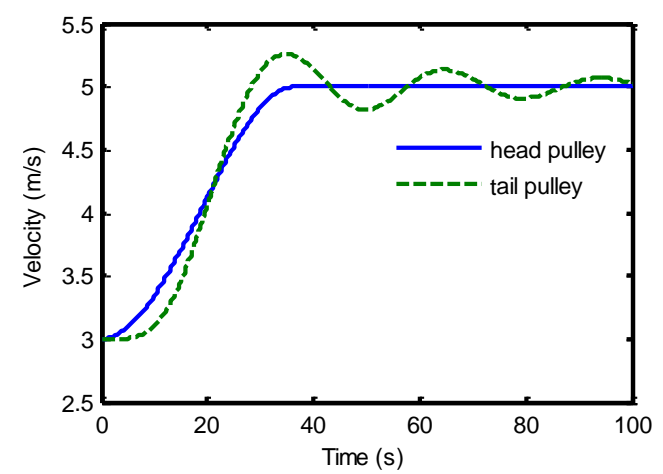

Fig. 6. Speed curves in speed regulation process.

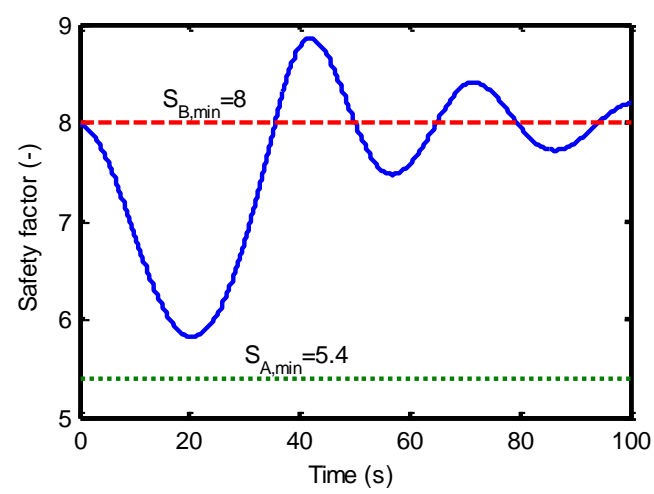

Fig. 7. Actual safety factor in speed regulation process.

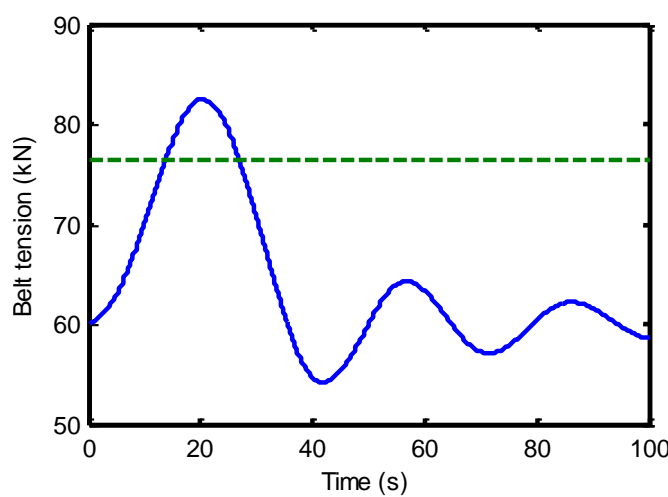

Fig. 8. Tensile force before the drive pulley in speed regulation process.

As discussed in Section II, to prevent the slip between the belt and drive pulley, the tension ratio between the belt before and after the drive pulley is expected no more than $e^{\mu \alpha}$. That means in this simulation for the specified conveyor system, the maximum belt tensile force should be less than $76.4 \mathrm{kN}$. However, the further simulation results in Fig. 8 show that at the time period between $14 \mathrm{~s}$ and $27 \mathrm{~s}$, the belt tensile force is larger than the permitted. The unexpected phenomenon implies in this acceleration process, there is a high risk of slipping between the belt and the drive pulley.

The unexpected high risk of slipping implies the estimation of acceleration is not sufficient to decide the demanded acceleration time in transient operation. To get the optimum acceleration time, simulations with different acceleration time are taken and Fig. 9 illustrates the simulation results. The simulation result suggests in this defined case study, the required acceleration time should be at least 47 seconds.

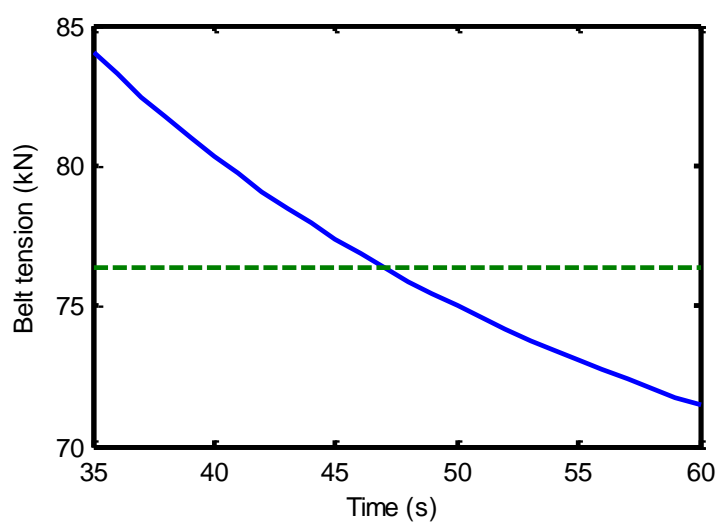

Fig. 9. Maximum belt tensile force with different acceleration

In this section, case of horizontal belt conveyor is studied. Based on finite element model, the simulations are carried out with calculated acceleration time. The analyses of belt dynamic behaviors implies that in transient operation, the risk of belt breaking is very small, however, the simulation results also show that during the acceleration, there is a high risk of slipping between the belt and the drive pulley. The further simulation suggests that for this defined belt conveyor, the acceleration time is at least 47 seconds to accelerate the conveyor from $3 \mathrm{~m} / \mathrm{s}$ to $5 \mathrm{~m} / \mathrm{s}$ with sinusoid acceleration profile. The method, estimating with calculations and correcting with simulations, will be used into practice to decide the acceleration in transient operation for belt conveyor speed control.

\section{CONCLUSION}

This paper presents a method estimating the demanded acceleration time in transient operation. Honoring the demanded safety factor and ratio between the tension before and after the drive pulley, the calculations are given to rough estimate the permitted acceleration and demanded acceleration time. Case of long horizontal belt conveyor is investigated. Simulations with finite element model are carried out and the belt dynamic behaviors in transient operation are analyzed to correct the demanded acceleration time. With regard to various speed regulation ranges and different acceleration profiles, further investigation will be undertaken.

\section{REFERENCES}

[1] Y. Pang, Intelligent Belt Conveyor Monitoring and Control, Netherlands TRAIL Research School, 2010.

[2] P. Stoop, "Energy management and saving systems for a belt convyeor," Master, Delft University of Technology, 2010.

[3] S. Drenkelford, "Energy saving solutions for belt conveyor systems," Master literature, 2013.

[4] S. Falkenberg and T. Wennekamp, "Doping of conveyor belt materials with nanostructured fillers to adapt innovative performance characteristics," in Proc. the IEEE International Conference on Automation and Logistics, 2008, pp. 1526-1533.

[5] A. Tapp, "Conveying technology-energy saving troughing idler technology," Bulk Solids Handling, vol. 20, pp. 437-450, 2000. 
[6] A. Mukhopadhyay, A. Chattopadhyay, R. Soni, and M. Bhattnagar, "Energy efficient idler for belt conveyor systems," Bulk Solids Handling, vol. 29, p. 214, 2009.

[7] A. Emadi, Energy-Efficient Electric Motors, Revised and Expanded, CRC Press, 2004.

[8] M. Yester, "The basics and cost savings of utilizing vertical conveyor technology," Bulk Solids Handling, vol. 17, pp. 357-368, 1997.

[9] A. Dalgleish and L. Grobler, "Measurement and verification of a motor sequencing controller on a conveyor belt," Energy, vol. 28, pp. 913-927, 2003.

[10] W. Daus, S. Koerber, and N. Becker, "Raw coal loading and belt conveyor system at nochten opencast mine," Braunkohle, vol. 50, pp. 117-130, 1998.

[11] Variable-Speed Drives for Belt-Conveyor Systems, 2000.

[12] J. Hiltermann, G. Lodewijks, D. L. Schott, J. C. Rijsenbrij, J. A. J. M. Dekkers, and Y. Pang, "A methodology to predict power savings of troughed belt conveyors by speed control," Particulate Science and Technology, vol. 29, pp. 14-27, 2011.

[13] Continuous Conveyors-Belt Conveyors for Loos Bulk Materials-Basics for Calculation and Dimensioning, 1982.

[14] J. Hiltermann, Reducing the Eletrical Power Consumption of Troughed Belt Conveyors by Speed Control, July 4, 2008.

[15] Y. Pang and G. Lodewijks, "Improving energy efficiency in material transport systems by fuzzy speed control," in Proc. the 20113 rd IEEE International Symposium on Logistics and Industrial Informatics (LINDI), 2011, pp. 159-164.

[16] H. Lauhoff, "Belt conveyor technology-speed control on belt conveyors-Does it really save energy?" Bulk Solids Handling, vol. 25, p. $368,2005$.

[17] S. Zhang and X. Xia, "A new energy calculation model of belt conveyor," in Proc. the Conference of the African Continent and Provides a Platform for acaDemics and Industry Professionals, 2009, pp. 1-6.

[18] L. B. Ristic and B. I. Jeftenic, "Implementation of fuzzy control to improve energy efficiency of variable speed bulk material transportation," IEEE Transactions, Industrial Electronics, vol. 59, pp. 2959-2969, 2012.

[19] G. Lodewijks, "Dynamics of belt systems," Doctor, Delft University of Technology, Faculty of Machanical Engineering and Marine Technology, Delft University of Technology, 1996.

[20] A. Nuttall and G. Lodewijks, "Dynamics of multiple drive belt conveyor systems," Particle and Particle Systems Characterization, vol. 24, pp. 365-369, 2007.

[21] G. Kuhnert and G. Schulz, "The origins of the" rope friction equation," Bulk Solids Handling, vol. 15, pp. 261-264, 1995.

[22] G. Lodewijks, "Non-linear dynamics of belt conveyor systems," Bulk Solids Handling, vol. 17, pp. 57-68, 1997.
[23] G. Li, Dynamics and Design of Belt Conveyor, China Machine Press, 1998.

[24] L. Nordell and Z. Ciozda, "Transient belt stresses during starting and stopping: Elastic response simulated by finite element methods," Bulk Solids Handling, vol. 4, pp. 93-98, 1984.

[25] P. Kulinowski, "Dynamic start-up calculations for belt conveyors with measured torque curves of fluid couplings," Hydrodynamic Power Transmission, pp. 443-448, 2004

[26] H. W. Ma, D. S. Li, X. H. Zhang, and Q. H. Mao, "Dynamic Simulation Analysis of Belt Rupture for Belt Conveyor," Applied Mechanics and Materials, vol. 313, pp. 1120-1124, 2013.

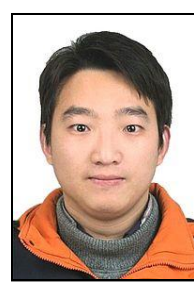

Daijie He was born in Jiangyou City, China in 1988. He is a PhD candidate of Delft University of Technology (TUD). He received his bachelor and master degree from College of Engineering and Technology, Southwest University, China in 2011 and 2013 respectively.

Awarded a scholarship under the State Scholarship Fund, he started his PhD study in 2013. His main domains of interest are bulk solids handling, transportation and logistics, modeling and simulation.

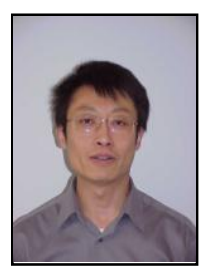

Yusong Pang was graduated in China with a MSc degree in electrical engineering. Since 2000 he worked at Practis B.V. and Seaview B.V. in the Netherlands. After his PhD research of intelligent belt conveyor monitoring and control in 2007, he worked at the Advisory Group of Industrial Installations of Royal Haskoning, Netherlands as a project engineer and mechanical engineer. Currently, he is an assistant professor in the Section of Transport Engineering and Logistics, Delft University of Technology, Netherlands.

His main research interests include reliability control and sustainability management in material transport

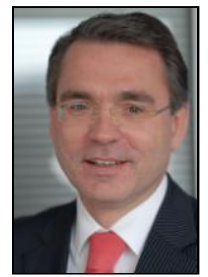

Gabriel Lodewijks studied mechanical engineering at Twente University and Delft University, Netherlands. He obtained a master degree in 1992 and a $\mathrm{PhD}$ on the dynamics of belt systems in 1996 . He is the president of Conveyor Experts BV, which he established in 1999. In 2000, he was appointed as a professor of the Department Transport Engineering and Logistics at the Faculty of Mechanical, Maritime and Materials Engineering. From 2002 , he was appointed as the chairman of the department and the vice dean of the faculty since 2011 .

His main interests include belt conveyor technology, automation of transport system, material engineering and dynamics. 